
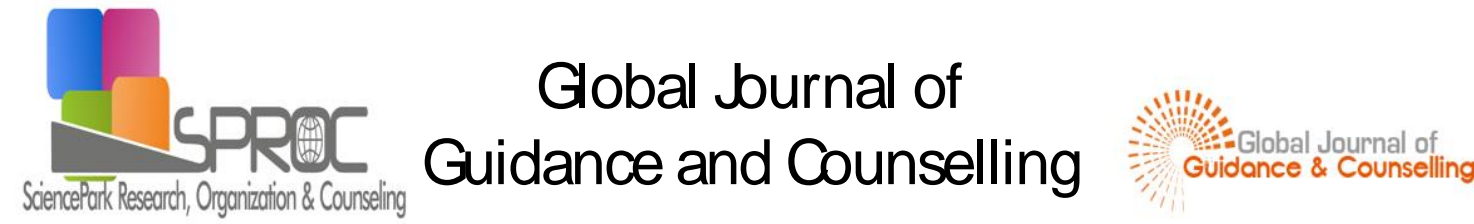

http://sproc.org/ojs/index.php/gigc

\title{
Investigating the effect of social capital on delinquency of 15-to- 19-year-old juveniles in shiraz
}

Zinab Adelmand *

Fatemeh Adelmand,

Tahmineh Adelmand,

Maryam Zarnaghash,

Suggested Citation:

c

G

J

G

Abstract

Zinab Adelmand, 
1. Introduction

2. Method 
$G \quad J \quad G \quad C$

3. Findings 
4. Conclusion

\section{References}

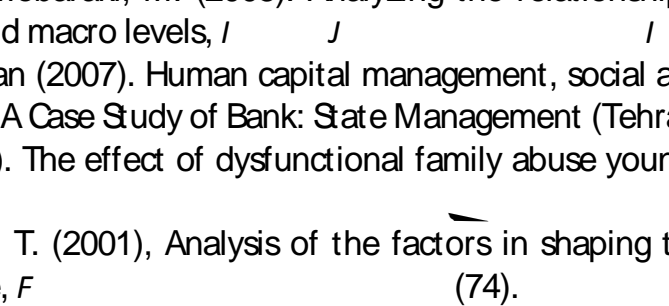

